\title{
Applying E-marketing Methodologies In The Mobile Industry: The Case of Orange - Jordan \\ ${ }^{1}$ Rania A. Bakeir , ${ }^{2}$ Emad Abu-Shanab and ${ }^{3}$ Shadi Al Biss \\ ${ }^{1}$ Yarmouk University, Jordan, rbakeir@yahoo.com \\ ${ }^{2}$ Yarmouk University, Jordan, abushanab@ yu.edu.jo \\ ${ }^{3}$ Orange Jordan (Jordan Telecom Group), Jordan, shadi.albaess@ orange-jtg.jo
}

\begin{abstract}
This paper explores the concepts of e-marketing and utilizes a case study focusing on Orange mobile firm. The study utilized some reports, data and the company website to identify the e-marketing strategy used by Orange and to recommend some remedies to improve their e-marketing strategy. The study uses an online tool to conduct some test on Orange's website and explore the firm's website using qualitative some tools and aspects of e-marketing concept. The output of this paper is aimed at aiding Orange to gain experience from what is working in other countries or organizations in relation to e-marketing and to know how it can benefit from using e-marketing as an effective tool to gain competitive advantage.
\end{abstract}

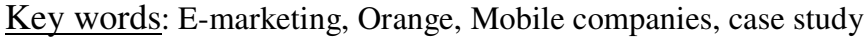

\section{Introduction}

The Internet offers companies a great opportunity to market new and old goods and services to more existing and new customers than before. Reaching customers and building this customer loyalty through delivering quality, convenience, price competitiveness, and the right products and services, begins with a solid e-marketing plan.

E-marketing means using the Internet as a branding, marketing and sales medium. Online marketing have many advantages such as pull vs. push, cost effectiveness, $24 * 7$, global reach, measurability, scalability, targeting and personalization, direct to customer and tracking. E-marketing through the Internet adds the advantage of tracking everything, where customer's behaviors and transactions can be seen instantly. E-marketing is a way to get your product/service/brand to the whole world in a glimpse through the effective use of this huge architecture named the World Wide Web (WWW).

Today e-marketing plans must do more than tell a story of innovative technology, or develop information technologies geared to attracting online visitors and developing market share. Effective marketing programs and strategies that quantify goals and provide measurable impact are the means to success in the new economy [17].

This paper will try to present Orange Company and its experiences in the mobile telecommunications sector, where the firm is moving towards e-marketing applications. The telecommunications industry is witnessing fierce competition and a low switching cost for customer. This paper aims at studying the e-marketing tools that Orange has used including their web site and will compare between Orange web site and other Jordanian telecom companies' websites.

This paper is organized as follows: in section 2 we present an overview about e-marketing system. In section 3, the history of Orange Company, and its e-marketing system are outlined. Conclusions and future work are provided in section 4. Finally, the paper limitations and recommendations are discussed in section 5 and 6 respectively.

\section{Literature review}

E-marketing is becoming more attractive as firms are utilizing the opportunities the Internet is offering mainly through the wide exposure to their existing and new customers. The following literature will explore previous work related to emarketing and research in the area of mobile services.

\subsection{The differences between marketing, e-marketing, Internet marketing and interactive marketing:}

E-marketing is essentially a subset of marketing. The American Marketing Association (AMA, 2004) defines marketing as an organizational function and a set of processes for creating, communicating and delivering value to customers and for managing customer relationship in ways that benefit the organization and its stakeholders. Therefore e-marketing is one aspect of an organizational function and a set of processes for creating, communicating and delivering value to customers, and for managing customer relationships in ways that benefit the organization and its stakeholders using electronic means. As such an aspect, e-Marketing has its own approaches and tools that contribute to the achievement of marketing goals and objectives [15].

There is no real difference between e-marketing and Internet marketing. The advent of the Internet resulted in a wide adoption of web technologies because of its cost and convenience for organizations and customers. However, with the arrival of mobile technologies and interactive television, both terms tend to be stretched to include these new media technologies. On the other hand, others would see e-marketing and Internet marketing as totally different, for example Chaffey (2006) considers Internet marketing as achieving marketing objectives through applying digital technologies and e-marketing as achieving marketing objectives through the use of electronic communications technology.

E-marketing is a broader term that describes any marketing activity performed via electronic medium, where interactive marketing is generally a subset of e-marketing that involves a certain level of interaction [16].

\subsection{Advantages of e-marketing:}

Research in the area of e-marketing identified a long list of advantages that made the topic one of the important ones for firms and customers. The advantages reported are the following: speedy access, track able, reaching a wider public, 
efficient use of buyer time, connecting to target/specific audiences, no restrictions on content, world-wide showcase, easy to manage, efficient use of technology, modern touch, savings in postal charges, simple to use, and 24/7 availability [10].

\subsection{The e-marketing conceptual framework:}

E-marketing is a concept that relates to other theories imported from environmental analysis and consumer behavior models. When dealing with wide networks we can emphasize the importance of external factors. On the other hand, traditional views of marketing are still valid. The framework shown in Figure 1 links five factors: internal forces, external forces, past web and firm performance, current web and firm performance, and e-marketing strategy. Marketing strategy is defined in terms of the $4 \mathrm{Ws}$ and they are: web-design, web-promotion, web-price, and web-CRM (customer relationship management).

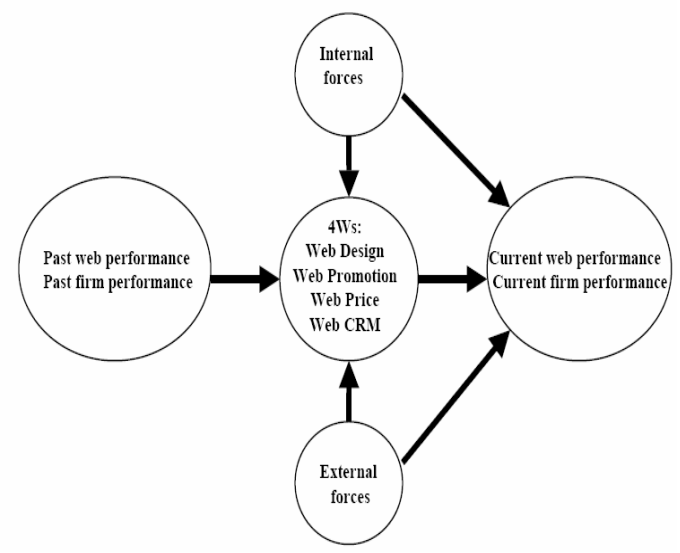

Figure 1: The e-marketing framework and the 4w's Source (Carmen Lages, Luís Filipe Lages and Paulo Rita ,2004)

The Performance levels result from the co-alignment among strategy and the firm's context (i.e., the internal and external forces) and that organizational culture might be irrelevant when implementing web-strategies. Also, web-marketing strategy using the $4 \mathrm{w}$ 's will result in an increase in efficiency within established marketing functions. Second, the technology of e-marketing transforms many marketing strategies resulting in new business models that add customer value and/or increase company profitability. Also, we should consider firm performance as well as website performance evaluation and think that they are on the same level of importance. Focusing on web performance many e-commerce companies collect data related to cost and usage of their websites, few of them understand, in detail, how well such information measures their sites' performance or how this performance compares with that of competing sites.

Most measures of web-performance track variations in traffic-page views, advertising impressions served, unique users, and so on. But the foundation of long-term performance is lifetime customer value; the revenue customers generate over their lives, less the cost of acquiring, converting, and retaining them [7].

\subsection{Tips for more effective use of the Internet in meeting marketing to buyers:}

- Make sure the campaign is 'exciting', original and differentiated

- Before using the web, always talk personally to the target buyer.

- Work on improving the quality of the chosen audience

- Be client-driven

- Be honest, clear and specific

- Do more, now, faster

- Develop a 'customized' section of your website

- Personalize your messages

- Be fully accessible in only a few clicks

- Use a different approach and language online to that applied offline

- have a distinct and specialized e-marketing strategy

- use bullet-point textual descriptions and be brief [10], [11].

\subsection{Rules to control e-marketing:}

Rules established to control e-marketing when using electronic messages sent by e-mail, instant messaging and short message services (SMS) and multimedia message services (MMS) as not to be considered as spam to the users. Therefore e-marketing code of practice has been developed to establish comprehensive industry rules and guidelines for sending commercial electronic messages, which gives benefits to both consumers and industry.

The anticipated benefits brought to consumers by this control process range from the expectation of appropriate industry behavior in relation to sending commercial electronic messages and the gaining of consent. Second, a reduction in the incidence of unsolicited commercial messages sent by members of the e-marketing industry. Third, a clear understanding of the e-marketing industry's processes and benchmarks in respect to commercial electronic messages. Forth, a clear and comprehensive identification of the senders and/or authorizers of commercial electronic messages. Fifth, a clear and 
transparent means of unsubscribing to/and withdrawing consent to receive future messages. Finally, an efficient and fair method of having complaints handled by the e-marketing industry.

On the other hand, benefits brought to industry should result in the reduction of complaints made to members of the emarketing industry. Also, it will give the public greater confidence in the e-marketing industry's compliance. Finally, different legal issues should be discussed such as age sensitive content (for example sending promotion on alcoholic beverage for people less than 18 years) [8].

\subsection{Steps in e-marketing strategy :}

1. Email Address, available e-mail address is the first step in an e-marketing strategy.

2. Personal and Business Websites, the second step in utilizing websites towards reaching customers and providing needed information for them.

3. E-Newsletter (E-Mail Campaign): This step consists of four elements: building mailing lists, designing the newsletter, emailing the newsletter, and analyzing the results. Based on the inspection of Orange website, this service is not provided through online services.

4. Ranking high in search engines: Users doing searches are happy with websites listed on the first page of the search engine. This can be achieved by optimizing your website for search engines, the techniques are demanding but the following three factors will go a long way in achieving the ranking: make sure you have relevant title for every page of your website, well structured and user friendly website, and lots of websites are linked to yours.

5. Blogging: There are two ways to promote your services through blogging. The first one is providing feedback/comments on someone's blog. The second is creating your own blog (Orange has its own blog).

6. Social networking websites: Social network sites like MySpace and Facebook provide a major platform for collaboration and establishing your identity with like- minded people. There are some social network sites that will let you post your audio/video clips, such as YouTube.com. (Orange has joined some social network ex. Maktoob.com)

7. Establish credibility: You can promote yourself by becoming an "Active Net Citizen" for example you can write press releases when you have something to announce and make statements (Orange publish a yearly press release about its financial situation in the market) [9].

\subsection{Lists of disadvantages of e-marketing:}

E-marketing has some disadvantages like: no personal contact, flooded/crowded market, not targeted to individual needs, too much information, not always measurable, questions can't be answered, no 'feelings' involved directly, need to update regularly, not everybody participate to enhance, no eye-to-eye contact, "has anyone actually read you?", too much choices, not effective on its own, buyers overwhelmed with too classical marketing initiatives many unsolicited messages, products look better online than they are actually, campaigns can seem aggressive, can't tailor-make offers, spam, seeing is believing - but not possible via the Internet [10],[11].

\section{Orange background}

Orange is the key brand of France Telecom, one of the world's leading telecommunications operators. France Telecom serves more than 177 million customers around the world. In 2000, France Telecom became a strategic partner of Jordan Telecom and gradually increased its share in the Group until it became the majority shareholder with $51 \%$ of the share capital. Jordan Telecom was created in 1971 under the name "Telecommunications Corporation", which was then totally owned by the Jordanian government. In 1997 the corporation was privatized and became Jordan Telecommunications Company, providing fixed line services. Jordan Telecom Group decided in 2006 to integrate its fixed, mobile, Internet and content, businesses and its wholesale offering under the Jordan Telecom Group to create an integrated operator in Jordan. The Jordan Telecom Group now serves nearly 2.5 million customers providing integrated communication technologies at affordable prices. In 2007, the Jordan Telecom Group adopted the Orange brand for all its services as part of a strategic plan aimed at providing Jordan with world class services.

Jordan Telecom Group (JTG) plays a prominent role in the information and communications technology sector. It's fixed, mobile, and internet services constitute the real base for the Kingdom's telecommunications renaissance and contribute to its integration with regional and world countries.

In the biggest integration of its kind in the market, the JTG, in 2006, combined its four companies under one umbrella becoming the sole integrated operator in Jordan. This step aimed at providing the Jordanian market with the standardized world class services of the Orange brand creating a clear difference in the lives of people who joined the Orange global family.

Since then, Orange Jordan has made available the best telecommunications services for its customers through offering various and comprehensive services at affordable prices and in line with its values and principles to fulfill the requirements of the Jordanian citizens and meet the needs of the local market.

To continue to meet the demands of its customers and to drive better customer service, which is a key differentiator in today's competitive marketplace, the Group restructured its business units on the basis of the market segments they address:

1. Home, which specializes in offering fixed and Internet offers to residential customers.

2. Small \& Medium business (SMBs).

3. Personal, this specializes in meeting the requirements of customers looking for mobile line solutions with highly focused customer service and differentiated offers. 
4. Enterprise, which specializes in gathering and combining all aspects of the relationship with corporate customers such as companies, banks, public and private institutions under one (mobile, fixed and internet) organization instead of three.

JTG Wholesale specializes in managing the relations between the Group's networks and all national and international operators. Orange Innovations \& Corporate Integrated Solutions handles Group's innovative offers such as Internet Protocol TV (IPTV) and manages projects implementation. It provides also turnkey solutions to the corporate customers.

This structure has also allowed the Group to add value plus simplicity to the life of its customers which has consequently distinguished the Group's status in Jordan. With its ability to call upon the vast expertise of its French partner and main shareholder, the JTG continues to provide the market with all that the world telecom industry has to offer, supported by its state of the art digital network that stretches to cover the whole Kingdom. The Group now serves customers with appropriate communication technologies, at affordable prices, and world-class service.

Orange mission is "to provide, everywhere in the Kingdom, residential and business customers with the appropriate technologies of communication, at affordable prices in line with the social responsibility of the local community, in order to anticipate and satisfy their specific needs, at a world class service level".

\section{Telecom organization \& Jordan market environment}

The telecommunications market is undergoing a triple revolution: technological, regulatory, and competitive. In this environment, the group's strategy is founded on a pioneering model of an integrated operator offering its customers a new generation of telecommunications services.

In Jordan, the group offers fixed line, internet and mobile services consolidating the Jordan Telecom Group. The strategic partnership between the two groups (French and Jordanian) began in 2000. Jordan Telecom Group now serves more than 2.3 million subscribers, offering them innovative communication technologies at competitive tariffs and world-class service.

At the end of 2007, with more than 1.5 mobile customers, the group was the second mobile service provider in the country after Fast Link (Zain) but before Umniah the third player in Jordanian telecom market, representing a market share around $34 \%$ and its network covered $97.7 \%$ of the population in Jordan.

In providing a full complement of fixed telecom services to more than 600,000 customers, Orange fixed priorities include developing and improving the fixed voice telephone network, extending the reach of the Kingdom's data transmission network to ensure that every citizen of Jordan has the opportunity of being globally connected.

Today Orange is the leading Internet Service Provider (ISP) in Jordan with more than 50\% market share. In bringing its fresh approach to the Jordanian's on-line scene, Orange leads the innovation in the market through the introduction of services such as broadband access ADSL, CoolNet pre-paid Internet cards, Internet through 0900 service, data communication and Internet roaming, to name just a few.

Convergence between different types of communication and media services is currently driving the innovation and development of key global telecommunications markets. The group intends to build better value services by combining not only the management teams of its group companies under a single team and leadership structure, but also by leveraging the integration of each company's specialization into better-value service packages available to consumers on a single service basis. Jordan Telecom Group Foundation continues to support the education sector in Jordan through concrete involvement and actions.

\section{Financial analysis}

5.1. Market Share

Orange Business Services provide communications solutions and services. Orange's stake in MobileCom (Petra Jordanian Mobile Telecommunications Co.) is $51 \%$ share in Jordan Telecom [12] as seen in the table below:

Table 1: Market analysis of Orange

\begin{tabular}{|c|c|c|c|c|}
\hline key figures on $12 / 31$ & 2004 & 2005 & 2006 & 2007 \\
\hline \multicolumn{5}{|c|}{ personal communication services } \\
\hline Market penetration rate & $30,1 \%$ & $52,6 \%$ & $54,1 \%$ & $65,1 \%$ \\
\hline $\begin{array}{l}\text { Number of customers } \\
(000) \mathrm{s}\end{array}$ & 455 & 751 & 1195 & 1514 \\
\hline Market share & $27,8 \%$ & $22,6 \%$ & $\begin{array}{l}31,0 \\
\%\end{array}$ & $33,7 \%$ \\
\hline \multicolumn{5}{|c|}{ home communication services } \\
\hline $\begin{array}{l}\text { Number of fixed line } \\
\text { customers }(000) \mathrm{s}\end{array}$ & 637 & 251 & 614 & 559 \\
\hline $\begin{array}{l}\text { Number of internet } \\
\text { clients }(000) \mathrm{s}\end{array}$ & non & non & 33 & 59 \\
\hline
\end{tabular}

\subsection{Revenues}

Revenues registered increased in earnings by 0.9 percent, or JD3.5 million, from JD397.9 million in 2007 to reach for the first time more than JD400 million at JD401.4 million in 2008. Mobile increased the subscriber base by 2.6 percent, from 1.71 million at the end of 2007, generating earnings of JD187 million compared to JD183.5 million at the end of 2007 [5].

\subsection{Jordan Telecom Group Subscribes}


The number of Jordan Telecom Group total subscribers climbed by 3.4\% to reach 2,521.1 (K lines) in year 2008 compared to $2,437.0$ (K lines) in year 2007 [5].

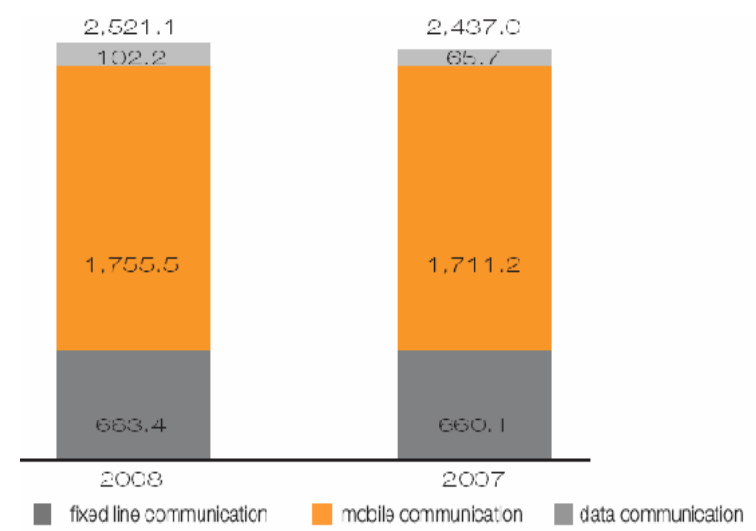

Figure 2: orange subscribes, Source Jordan Telecom Group annual report,2008

\subsection{OPEX versus EBITDA}

Operating Expenses (OPEX) consists of cost of services, selling and distribution expenses, administration expenses, government revenue share, brand fees and management fees. Earnings before Interest, Tax, Depreciation and Amortization (EBITDA) consist of sales of services less operating expenses.

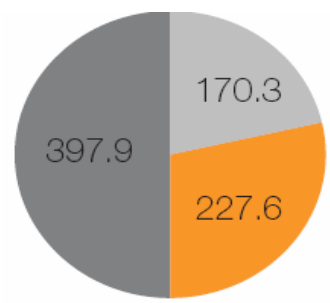

2007

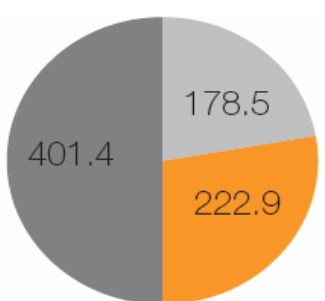

2008

revenues $\square$ OPEX $\square$ EBITDA

Figure 3: OPEX versus EBITDA, Source Jordan Telecom Group annual report,2008

\section{E-marketing activities in Orange}

6.1. Orange channels to reach customers

Orange employs the following techniques:

1. ATL channels: (Above The Line) This is provided through TV, radio, newspapers and magazines.

2. BTL channels: (Bellow The Line) This provided through posters and brochures.

3. Direct Marketing: This is done through two means:

- ONLINE channels: This is provided through their website, SMS, MMS and emails.

- Bulk SMS: when one unique message is sent to multiple recipients. This is an ideal broadcasting technology to communicate via mobile phones.

\subsection{Orange Digital marketing tools}

1. SMS (short message services) it's a wireless messaging service that permits the transmission of a short text message from and/or to a digital wireless terminal.

2. Website: through Orange own website, maktoob.com and Orangemail.jo websites.

3. E-mails: for members of email@ orange.com.

4. MMS (multimedia message services) which allows wireless customers to send and receive messages that contain much more than text including formatted text, graphics, photographs, and audio and video clips.

5. Vocal services: including Interactive Voice Response services (IVR), 0800 services (toll free), Voice mail service and VSMS service.

\subsection{Orange website Analysis}

Orange website is Orange Internet portal. Orange.jo is a hub of sources and links. It acts as a gateway that will provide customers with needed tools and services. Orange has established its own website to support customers' needs. All the information about orange products, announcements of new products, e-payments, news about promotions, Orange blog, yellow and white pages, search engine, free information about available movies on Jordan cinemas, free games, horoscope, Jordanian weather news and orange email is available through their website. 
Their website can be considered a rich website full of valuable information about their organization and other information that could support customers.

The problem with the Jordanian market is mainly in building the interest within individuals to use and trust the Internet for purchasing products or services online. Moreover, most Jordanian homes don't have ADSL connections. Arab Advisors' survey of Jordan's internet users in 2009 found that only $11.7 \%$ of the total households have ADSL connection. However, the number of internet users increases continuously year over year. The number of Orange internet subscribers rose by $50.4 \%$ at the end of 2008 compared to the end of 2007 [5].

This study utilized the capabilities of Alexa website services to analyze the traffic through Orange website and compare it with Umniah and Zain websites (major competitors of Orange in the mobile service sector).

Alexa is a subsidiary company of Amazon.com that was founded in 1996; ALEXA was originally an abbreviation for Address Lookup EXperts Authority and it is known for its toolbar and website. Once installed, the toolbar collects data on browsing behavior which is transmitted to the website where it is stored and analyzed and is the basis for the company's web traffic reporting. Alexa's Web site is built on the notion that timely and relevant information is essential to a vital web experience.

The result of the traffic ranking is depicted in the following graphs (Figures 4, 5, 6, \& 7). The traffic used for Orange in this analysis for the comparison between Orange, Zain and Umniah main websites not the Jordanian (.Jo), this limits the analysis related to Umniah to the Jordanian market as the organization is available only in Jordan.

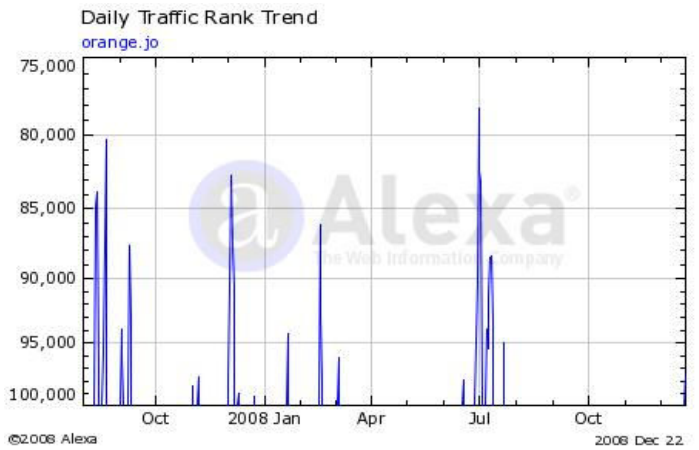

Figure 4: Daily traffic trend for orange.jo website from Oct 2007-Oct2008. Source http://www.alexa.com

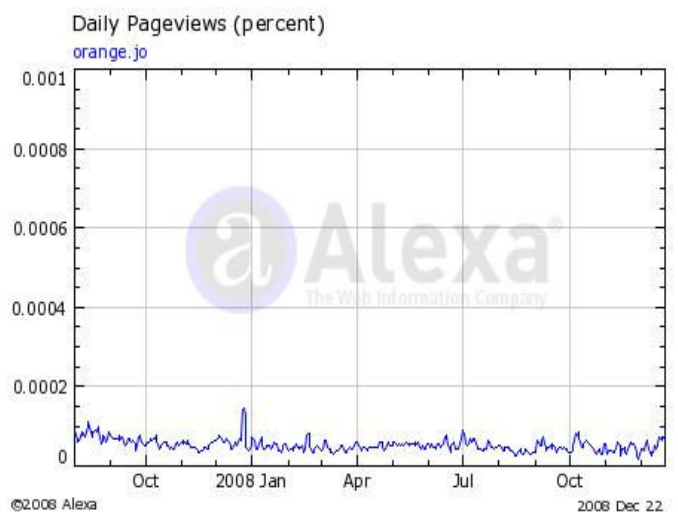

Figure 5: Daily page preview/percent for orange.jo website from Oct 2007-oct2008. Source http://www.alexa.com

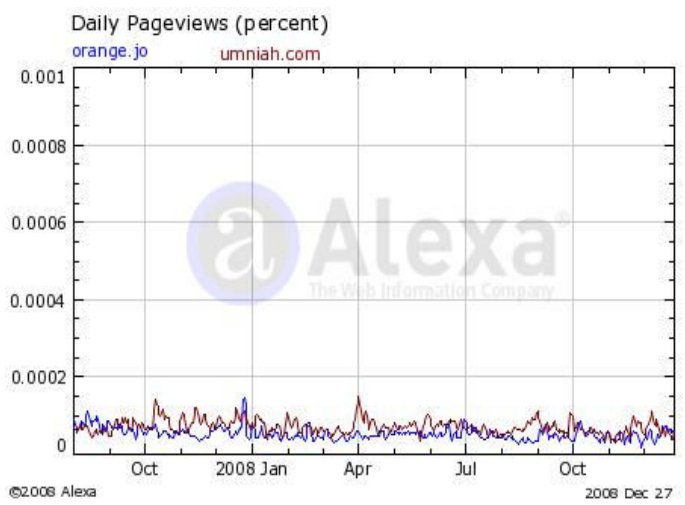

Figure 6: Comparing daily preview between orange.jo \& umniah.com websites From Oct 2007-oct2008. Source http://www.alexa.com 


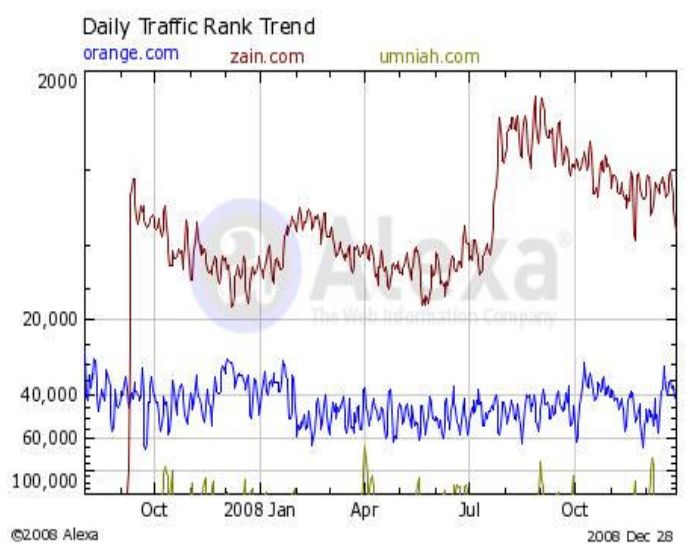

Figure 7: Comparing daily traffic trend for orange.com, zain.com \& umniah.com websites From Oct 2007-oct2008. Source http://www.alexa.com

This study utilized Alexa website as a tool to rank the top 100 popular sites (which is updated every 10 minutes) used in Jordan and results indicated that Orange website ranked 85 in the top 100 list. The top of the list was occupied by popular websites such as Google, yahoo, facebook ...etc.

Orange website reflects the firm's social responsibility towards the Jordanian society such as providing information about how to minimize electricity usage (rationing electricity campaigns), or not to use mobile phones while driving. Orange uses clickable banners on other websites such as maktoob.com and oranemail.jo to attract people to access their websites.

Based on analysis performed on Orange website and interviews conducted, Orange strategies come short in relation to their website. The firm doesn't filter users' information who use the website and doesn't study their customers attitude through the WEB. On the contrary, their information on WAP services is analyzed thoroughly and filtered (now they are studying add customer name on each message sent to customer through SMS and MMS as a signature). Orange tries to understand what WAP customers really want, what they do use, and what they prefer. Also, they try to understand their attitudes and segment them so they know what their targets are and how to acquire/achieve them through the WAP.

\subsection{Orange five P's Analysis}

1. Product

Orange provides different kinds of products and services to their customers. Table 2 lists the major products and services.

Table 2: Orange products and services

\begin{tabular}{|c|c|}
\hline Fixed telephone service & Supplementary services \\
\hline mobile phone service & Directory services \\
\hline ADSL service & Frame relay \\
\hline Call free service & Contact center services \\
\hline Leased line service & Video conferencing \\
\hline $\begin{array}{c}\text { Telex and telegraph } \\
\text { services }\end{array}$ & $\begin{array}{c}\text { Bundled services (voice+ } \\
\text { data) }\end{array}$ \\
\hline IP connectivity service & Wholesale services \\
\hline International calls & $\begin{array}{c}\text { handsets , and handset } \\
\text { packages }\end{array}$ \\
\hline
\end{tabular}

All these services are provided throw the website as well as through their offices. Orange tries to extend its product\& services range and find new products or services to offer. In September 2007, the CEO of orange announced the creation of a Techno-centre department in Amman, which will join the group's international network of Orange Labs, where they bring together researchers, marketing specialists and network engineers. The Amman Techno-centre's role will be to design and market new products and services for the entire France Telecom group, in Jordan as well as other countries where the group is present. It will enable all Jordanians to benefit from the expertise of the group's teams, particularly in the field of convergence.

\section{Price}

Orange has managed their pricing process to avoid conflict of pricing through offline or online pricing options .and sometimes Orange offer using some of its services through the Web in a cheaper mode than use it through any other distribution channels. For instance, RBT service has two distribution channels first one is calling the 090090900 extension to be a subscriber and to select the tone which is chargeable and the second is select the tone via website free of charge.

They do use the e-payment system on their website and they do provide all the needed services to customers to pay their bills through their website. But you cannot charge your mobile for example by using the electronic scratch card or electronic recharge, however, they have provided information about how to use scratch card off line after buying them from any offline dealer. Also, for the e-payment, organization provide terms and conditions which do not encourage its customers to use them but maybe make them fear from using the electronic channels as you will see bellow from their conditions on visa card holders : 
"Orange does not make any express or implied warranties, representations or endorsements whatsoever with regard to the Service. Orange would not be liable for any cost or damage arising either directly or indirectly from any such transaction. It is solely customer's responsibility to evaluate the accuracy, completeness and usefulness of all information he needs to provide through the service or on the Internet generally. Orange is not responsible for any wrong payment entry and the payment will be uploaded to the customer's account and it will not be refundable at all".

Also, they ask customers to agree to indemnify, "defend and hold harmless Orange, its officers, directors, employees, agents, licensors, suppliers and any third party information providers to the Service from and against all losses, expenses, damages and costs, including reasonable attorneys' fees, resulting from any violation or breach of these terms and conditions by customer. Notwithstanding the following, customer hold Orange free and harmless from suit or action arising from improper use of data, unauthorized intrusion into the site, unlawful exposure of data and misuse of credit card".

As seen from the previous terms and conditions it does not protect the customer's information and it does not provide any kind of information about the laws that could support the customers.

\section{Promotion}

Orange offers different kinds of promotions through their website as well as through other channels. Also, there website does not offer online only campaigns but do provide special online promotions such as the RBT (Ring Back Tone). Orange has a separate communication department in order to handle all the promotional activities in accordance with marketing department.

\section{Place}

As mentioned before Orange has managed their pricing process to avoid conflict of pricing through offline or online pricing options. So the same products, services and pricing will be found no matter what are the channels that customer going to use. Also, Orange has many physical outlets in all Jordanian cities in order to facilitate communication and reach the customers effectively.

\section{People}

\section{Services (people, process, physical evidence)}

The web site is automated and offers self-service for customers.

6. Process

The organization has changed their process and updated their services to adopt with new technologies to meet customer needs. They have already changed their process to start accept e-payment for customers fixed line bell.

\section{Physical evidence}

Orange website is an easy to use website with user friendly interface that supports Orange brand. Appendix B identifies measures of "physical evidence" depicted on Orange's website.

\section{How can Orange improve}

Orange should increase its efficiency for the renewal processes and the adoption of the new information technology infrastructure. While orange website is one of the best websites in Jordan and provides a user friendly interface, it also suffers from some deficiencies in the way they manage their web site. As mentioned before, and for example, they don't track or filter customer information through the web, only through the mobile services. Also, there is no control on web channel performance while they do control their mobile channels and evaluate their performance (such as knowing about demand of Arabic songs on the RBT service). So, it is recommended that they implement the same strategies that they do use with their WAP services on their WEB services.

This research recommends that Orange use the 4 web marketing strategies with their customers and they are:

1. Bring them in

2. Serve them well

3. Learn about them

4. Bring them back

Orange website lacks some services such as "tell a friend" service or "news letter email campaign" and they don't attract their customers to use their website for example by providing only on-Internet related/specific products. Actually while Jordanian people are not attracted to using the web service as they are cost sensitive, they need something to motivate them to use the web service such as special promotions provided only through the website as the RBT service.

They have also to use mail in their communication with their customers, but be careful not to spam them and they have to learn from other countries experience such as the Australian codes to control the spam [8].

\section{Conclusions}

This paper concluded to the fact that e-marketing is an effective tool if we use it in an effective way. Any organization can gain huge benefits and sustain its competitive advantage by using the e-business tools. This research analyzed Orange emarketing strategy and focused on their website. The study utilized an online tool (Alexa) and some qualitative techniques in providing an accurate picture that depicts Orange's practices in e-marketing.

E-marketing is a vital tool if used effectively by organizations would yield substantial results towards increasing market share and retain, acquire and extend new customers. The Jordanian market indicates a small number of web users, but promises with an increase in the coming few years. If orange doesn't start its e-business now and try to attract their customers to use their web site it's going to be too late to start later. They should start now, to give time to learn from their 
mistakes and to take advantage from their experiences. Orange can be the leader of e-marketing in the telecom market because of their experience and initiative to exploit this channel. Future will carry some rewards for Orange as they have their own website and previous experience from their WAP services; it will be easier for them to use the same strategies on the WEB.

\section{References}

[1] www.orange.com, retrieved at 2/1/2009

[2] www.orange.jo, retrieved at $2 / 1 / 2009$

[3] http://www.alexa.com, retrieved at 2/1/2009, 28/12/2008

[4] E-marketing and planning paper, edited by Dr. Emad Abu Shanab

[5] Jordan Telecom Group annual report,2008

[6] Orange Jordan financial report for year 2007.

[7] "The Relationship between E-Marketing Strategy and Performance: A Conceptual Framework in a Web Context", 2004, (Carmen Lages, Luís Filipe Lages and Paulo Rita)

[8] "Australian marketing Code of Practice", March 2005, http://www.acma.gov.au/webwr/telcomm/industry_codes/codes/australian\%20emarketing\%20code\%20of\%20practice.pdf

[9] "A Seven Step e-Marketing Strategy" , July 2, 2008,Max Haroon

[10] "Meetings Marketing on the Internet", January 2008, IMEX research paper http://www.imex-frankfurt.com

[11] "Meetings Marketing on the Internet", Feb 2009, IMEX research paper http://www.imex-frankfurt.com

[12] "E-Marketing: Innovative \& Cost Effective Marketing ", 14/september/2007, OMLogic Consulting team

[13] Jordan Telecom Group report, Amman, 4 September 2007.

[14] Mr. Shadi Al-Biss , marketing officer, meeting at office, 22/1/2008 , 10a.m

[15] Mr. Ahmed Salloum, programmer, meeting at office, 22/1/2008, 10a.m

[16] "E-marketing, what's e-marketing?",2009, http://www.marketingteacher.com.

[17] "Principles of e-Marketing" ,2009, Dejan Petrovic.

[18] "E-marketing and planning :accountability and emitrics",2000,Embillex software white paper.

\section{Appendix A: Questionnaire and Interview questions used}

1. What is the percentage of Jordan market share do orange own?

2. Who are the competitors of orange on Jordan market? Who are the most powerful one?

3. What is the thing (service or product) that orange do own and differentiate it from other competitors (give the company competitive advantage)?

4. What is your most demanded product? Also for service?

5. Do you have any kind of on-line only products? What is it?

6. To what kinds of groups you divided your customers to (customer segmentation)(ex. young people, organizations , individuals....etc.)?

7. How do orange use their website to attract customers to it?

8. Did orange make e-advertising? How? On which web sites (if not on their own one)?

9. What kinds of on-line channels orange use? Ex. Websites, sending mails....etc.?

10. What are the services or products that orange do provides to their customers throw e-channels (ex. website)?

11. How do you attract your customers to come to your company? Which way is better \& return to you the largest no of customers?

12. How do you attract them to stay with you?

13. How do you attract your customers to use your website? Is there any special promotion for who do use the company website? Give me example about these promotions?

14. Do you offer provide any kind of products or services throw the web site? (Give an example please)?

15. What is the percentage of your customers who use your website and getting served?

16. Do you use your web site or any of your e-channels to take feedback from your customer? How?

17. Do you use any kind of keeping consumer profiles on the web sites? Do you filtering these information's?

18. Do you use any kind of observing your consumers throw the e-channels (even their mobiles ex. Web bugs, spy ware...etc) to know their purchasing behavior? (please explain)

19. What are orange objectives? Did your website reflect these objectives or help to achieve them? Where?

20. What's the percentage of company whole budget that being spends on web site and e-channels?

21. Have your website or e-channels return back what you have pay on them? 


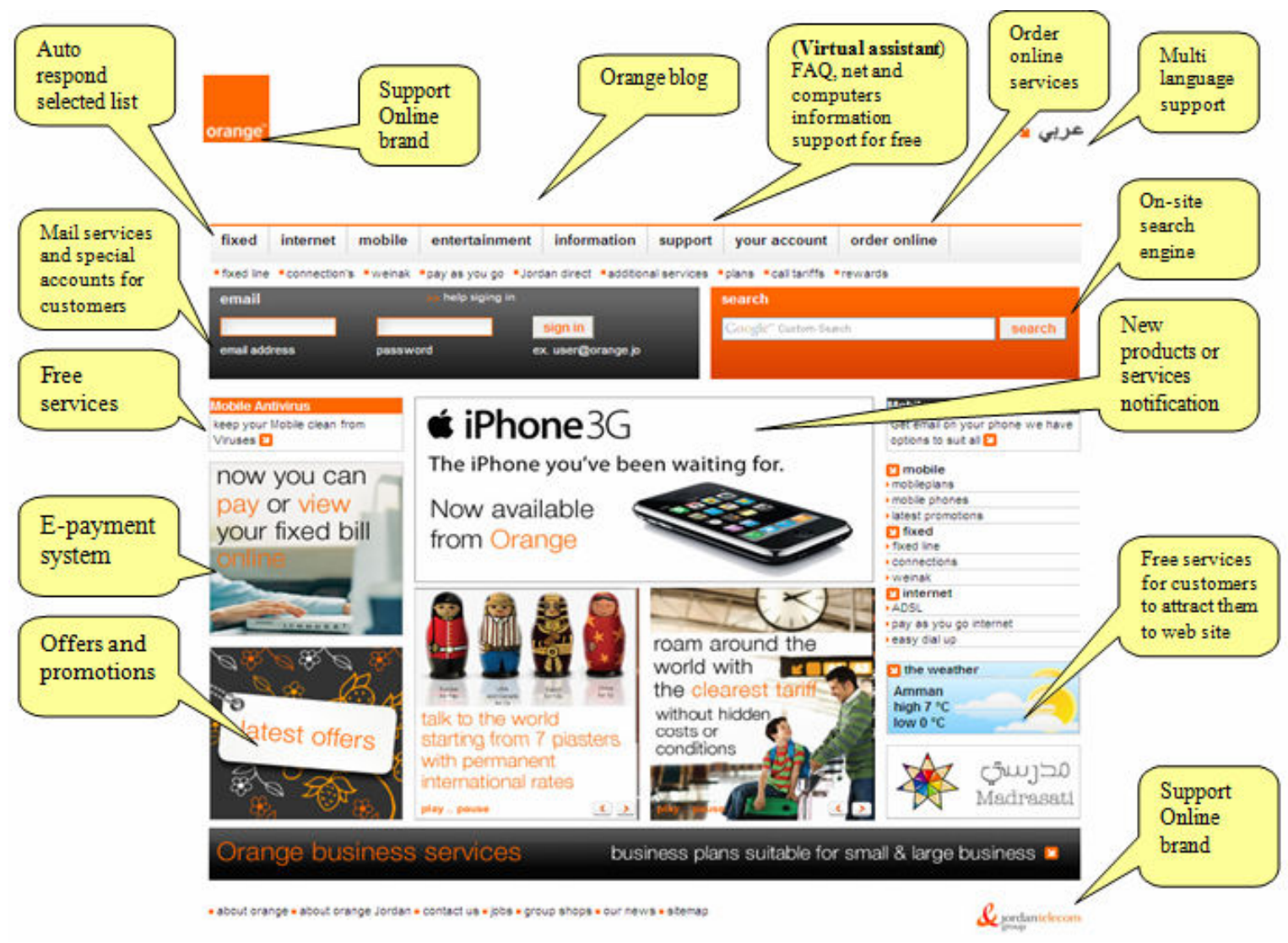

